\title{
Research on Robust Control of Gas Tungsten arc Welding System with the LMI Approach
}

\author{
Junfeng $\mathrm{Wu}^{*}$, Qiang Wang and Shengda Wang \\ Department of Automation, Harbin University of Science and Technology, 150080 Harbin, China
}

\begin{abstract}
By using the Lyapunov second method, the robust control and robust optimal control for the gas tungsten arc welding dynamic process whose underlying continuous-time systems are subjected to structured uncertainties are discussed in time-domain. As results, some sufficient conditions of robust stability and the corresponding robust control laws are derived. All these results are designed by solving a class of linear matrix inequalities (LMIs) and a class of dynamic optimization problem with $\boldsymbol{L M I s}$ constraints respectively. An example adapted under some experimental conditions in the dynamic process of gas tungsten arc welding system in which the controlled variable is the backside width and controlling variable welding speed, is worked out to illustrate the proposed results. It is shown in the paper that the sampling period is the crucial design parameter.
\end{abstract}

Keywords: robust control, linear matrix inequalities (LMIs), gas tungsten arc welding system.

\section{INTRODUCTION}

In recent years, much research concerning robust control of linear state-space models has been done. Over the past decades, two major approaches to this problem have been developed: the frequency-domain approach and the timedomain approach. Recently, a number of publications which consider the time-domain approach have appeared in the literature [1-8], In this approach, the Lyapunov stability theory [9-13] is used as a criterion for the analysis and synthesis of robust control systems. Moreover, the nominal system is assumed to be stable.

In computer control application, most of the control systems are sampled-data systems, which are the continuous objects under the control of computer. So it is significant to study robust control of sampled-data systems [14-18].

In this paper, robust control and robust optimal control problems for a class of sampled-data systems with structured uncertainty are considered using the second method of Lyapunov. The corresponding robust control laws are given, which are derived by solving a class of $\boldsymbol{L M I s}$ and a class of dynamic program problem with $\mathbf{L M I S}$ constraints respectively.

\section{PROBLEM FORMULATION AND PRELIMINARIES}

The systems considered in this paper are assumed to be a state-space model as follows

$x(t)=(A+\Delta A) x(t)+B u(t)$

*Address correspondence to this author at the Department of Automation, Harbin University of Science and Technology, 150080 Harbin, China; Tel: +86 045186390015;

E-mail:wu_jf@hrbust.edu.cn where $x(t) \in \Re^{n}$ is the state vector, $u(t) \in \mathfrak{R}^{m}$ is the control vector. $A \in \mathfrak{R}^{n \times n}, B \in \mathfrak{R}^{n \times m}$ are constant matrices. $\Delta A$ is time-invariant matrix which represents the structured uncertainty in the system model and is assumed to be of the form:

$$
\Delta A=\alpha \cdot A_{p}, \quad \alpha>0
$$

Discretizing the equation (1), yields

$$
x(k+1)=(G+\Delta G) x(k)+(H+\Delta H) u(k)
$$

Where

$$
\begin{aligned}
& G=\exp [A T] \\
& H=\int_{0}^{T} \exp [A \tau] d \tau B \\
& \Delta G=\exp [(A+\Delta A) T]-\exp [A T] \\
& =\exp [A T][\exp [\Delta A T]-1] \\
& \Delta H=\int_{0}^{T} \exp [(A+\Delta A) \tau] d \tau B-\int_{0}^{T} \exp [A \tau] d \tau B \\
& =\int_{0}^{T} \exp [A \tau][\exp [\Delta A \tau]-I] d \tau B
\end{aligned}
$$

When the sampling time $T$ is sufficient small, yields

$$
\exp [\Delta A T] \approx I+\Delta A T
$$

$$
\text { so }
$$

$$
\begin{aligned}
\Delta G & =\exp [A T] \Delta A T=\alpha \cdot G A_{p} T \\
\Delta H & =\int_{0}^{T} \exp [A \tau] \tau d \tau \Delta A B \\
& =H_{q} \Delta A B=\alpha H_{q} A_{p} B
\end{aligned}
$$


Definition 1 If there exists a state feedback control law $u(k)=K x(k)$ and a matrix $0<P^{T}=P \in \Re^{n \times n}$, which make the following inequality hold

$$
x(k+1)^{T} P x(k+1)-x(k)^{T} P x(k)<0
$$

then the controller is the robust controller of the discretetime model (3).

In the proof of main results in this paper, the following lemmas are needed.

Fact 1 Consider any two square matrices $Y$ and $W$ such that $Y=W^{T} W$, and there are two matrices $X$ and $Z$ of appropriate dimensions. Then for any vector $x$ with appropriate dimension and any constant $\varepsilon \in \Re^{+}$

$2 x^{T} X^{T} Y Z x \leq \varepsilon x^{T} X^{T} Y X x+\varepsilon^{-1} x^{T} Z^{T} Y Z x$

Fact 2 (Schur complement) Given constant matrices $\Omega_{1}, \Omega_{2}, \Omega_{3}$, where $\Omega_{1}=\Omega_{1}^{T}$ and $0<\Omega_{2}=\Omega_{2}^{T}$, then $\Omega_{1}+\Omega_{3}^{T} \Omega_{2}^{-1} \Omega_{3}<0$ if and only if

$$
\left[\begin{array}{cc}
\Omega_{1} & \Omega_{3}^{T} \\
\Omega_{3} & -\Omega_{2}
\end{array}\right]<0 \text { or }\left[\begin{array}{cc}
-\Omega_{2} & \Omega_{3} \\
\Omega_{3}^{T} & \Omega_{1}
\end{array}\right]<0
$$

\section{MAIN RESULTS}

In this section, according to the discrete-time model in section 2 and a given quadratic index, robust control and robust optimal control problems for sampled-data systems are studied. As a result, the corresponding robust control laws for sampled-data systems are derived.

\subsection{Design of General Controller}

Theorem 1 System (3) is robust stable via state feedback if there exist matrices

$0<Q^{T}=Q \in \mathfrak{R}^{n \times n}$ and $Y \in \mathfrak{R}^{m \times n}$

satisfying the following $\boldsymbol{L M I}$

Furthermore, the control law is given by

$u(k)=K x(k), K=Y Q^{-1}$

Proof (9) is equivalent to

$$
(1+\varepsilon)(G Q+H Y)^{T} Q^{-1}(G Q+H Y)
$$$$
+\left(1+\varepsilon^{-1}\right) \alpha^{2}\left[\left(\begin{array}{cc}
G & H_{q}
\end{array}\right)\left(\begin{array}{cc}
A_{p} & 0 \\
0 & A_{p}
\end{array}\right)\left(\begin{array}{c}
Q T \\
B Y
\end{array}\right)\right]^{T} Q^{-1}
$$

$\left[\left(\begin{array}{ll}G & H_{q}\end{array}\right)\left(\begin{array}{cc}A_{p} & 0 \\ 0 & A_{p}\end{array}\right)\left(\begin{array}{c}Q T \\ B Y\end{array}\right)\right]-Q<0$

that is

$$
\begin{aligned}
& (1+\varepsilon)(G Q+H Y)^{T} Q^{-1}(G Q+H Y)+\left(1+\varepsilon^{-1}\right) \\
& (\Delta G Q+\Delta H Y)^{T} Q^{-1}(\Delta G Q+\Delta H Y)-Q<0
\end{aligned}
$$

By fact 1, (12) hold if and only if

$$
\begin{aligned}
& (G Q+H Y)^{T} Q^{-1}(G Q+H Y)+2(G Q+H Y)^{T} Q^{-1}(\Delta G Q+\Delta H Y) \\
& +(\Delta G Q+\Delta H Y)^{T} Q^{-1}(\Delta G Q+\Delta H Y)-Q<0
\end{aligned}
$$

arranging it, yields

$$
\begin{gathered}
{[(G+\Delta G) Q+(H+\Delta H) Y]^{T} Q^{-1}[(G+\Delta G) Q} \\
+(H+\Delta H) Y]-Q<0
\end{gathered}
$$

let $K=Y Q^{-1}$, yields

$[(G+\Delta G)+(H+\Delta H) K]^{T} Q^{-1}$

$[(G+\Delta G)+(H+\Delta H) K]-Q<0$

let $V_{k}=x(k)^{T} Q^{-1} x(k), u(k)=K x(k)$, then

$$
\begin{aligned}
\Delta V_{k}= & V_{k+1}-V_{k} \\
= & x(k+1)^{T} Q^{-1} x(k+1)-x(k)^{T} Q^{-1} x(k) \\
= & x(k)^{T}\left\{[(G+\Delta G)+(H+\Delta H) K]^{T} Q^{-1}\right. \\
& \left.\quad[(G+\Delta G)+(H+\Delta H) K]-Q^{-1}\right\} x(k)<0
\end{aligned}
$$

so the state feedback controller is the robust controller of the system (3), and the sampled-data system (shown in Fig. 1) under the control of (10) is also asymptotically stable.

\subsection{Design of Guaranteed Cost Controller}

Consider the performance index

$$
\begin{aligned}
& {\left[\begin{array}{cc}
-Q & (G Q+H Y)^{T} \\
{\left[\left(\begin{array}{cc}
G & H_{q}
\end{array}\right)\left(\begin{array}{cc}
A_{p} & 0 \\
0 & A_{p}
\end{array}\right)\left(\begin{array}{c}
Q T \\
B Y
\end{array}\right)\right]^{T}} \\
{\left[\left(\begin{array}{cc}
G & H_{q}
\end{array}\right)\left(\begin{array}{cc}
(G Q+H Y) & 0 \\
A_{p} & 0 \\
0 & A_{p}
\end{array}\right)\left(\begin{array}{c}
Q T \\
B Y
\end{array}\right)\right]} \\
\begin{array}{cc}
-(1+\varepsilon)^{-1} Q \\
0
\end{array} & -\left(1+\varepsilon^{-1}\right)^{-1} \alpha^{-2} Q
\end{array}\right]<0} \\
& J=\sum_{k=0}^{\infty}\left[x(k)^{T} S x(k)+u(k)^{T} R u(k)\right]
\end{aligned}
$$

and the controller

$$
u(k)=K x(k)
$$

According to Lyapunov stability theory, the following theorem is derived.

Theorem 2 The controller (17) is guaranteed cost controller if there exists matrix $P^{T}=P>0$ satisfying

$$
\begin{aligned}
& {[(G+\Delta G)+(H+\Delta H) K]^{T} P} \\
& {[(G+\Delta G)+(H+\Delta H) K]-P+S+K^{T} R K \leq 0}
\end{aligned}
$$

\section{Proof let}

$$
\begin{aligned}
& x(k+1)^{T} P x(k+1)-x(k)^{T} P x(k) \\
& \leq-\left(x(k)^{T} S x(k)+u(k)^{T} R u(k)\right)
\end{aligned}
$$



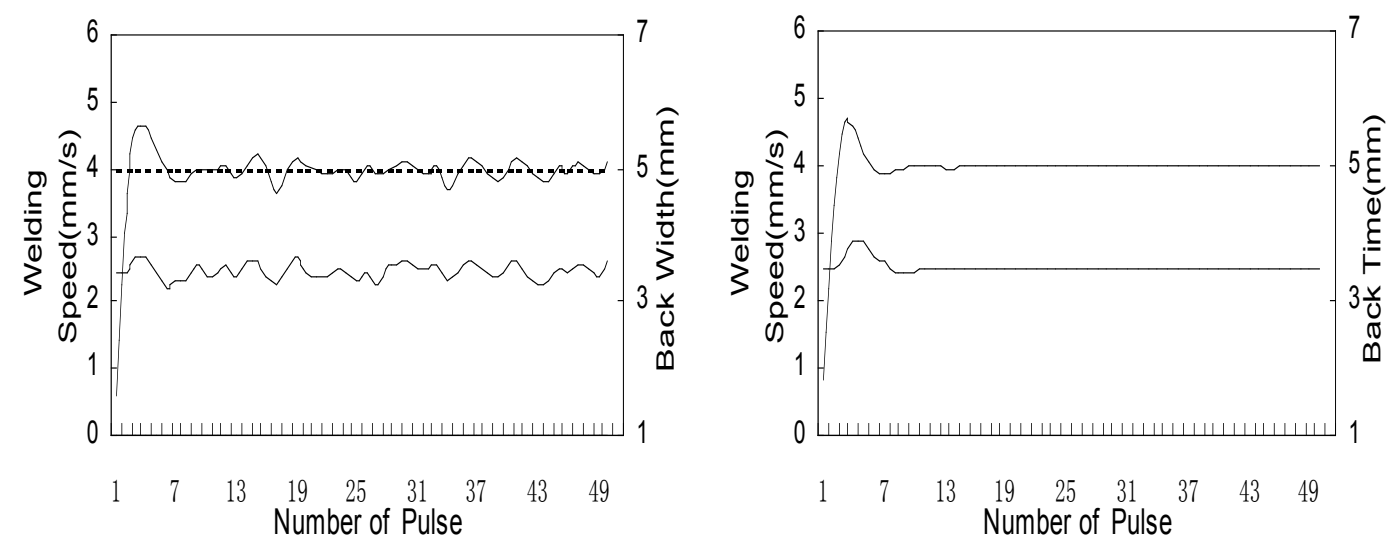

Fig. (1). Dynamic response curves of welding speed to backside width of weld pool with robust controller based on state observer response with disturbance response without disturbance.

then

$$
\begin{gathered}
J=\sum_{k=0}^{\infty}\left[x(k)^{T} S x(k)+u(k)^{T} R u(k)\right]=\sum_{k=0}^{\infty} x(k)^{T}\left[S+K^{T} R K\right] x(k) \\
\leq-\sum_{k=0}^{\infty}\left[x(k+1)^{T} P x(k+1)-x(k)^{T} P x(k)\right]=x(0)^{T} P x(0)
\end{gathered}
$$

apparently, the performance index is smaller than $x(0)^{T} \operatorname{Px}(0)$ for any $k_{\circ}$.

Moreover (19) is equivalent to

$$
\begin{aligned}
& x(k)^{T}\left\{[(G+\Delta G)+(H+\Delta H) K]^{T} P\right. \\
& [(G+\Delta G)+(H+\Delta H) K]-P\} x(k) \\
& \leq x(k)^{T}\left[S+K^{T} R K\right] x(k)
\end{aligned}
$$

so (18) holds.

Theorem 3 System (3) is quadratically stable via state feedback if given constant $\varepsilon \in \mathfrak{R}^{+}$there exist matrices $0<Q^{T}=Q \in \mathfrak{R}^{n \times n}$ and $Y \in \mathfrak{R}^{m \times n}$ satisfying

and the guaranteed cost controller is given by

$u(k)=K x(k), K=Y Q^{-1}$

Proof By lemma 2, (21) is equivalent to

$Y^{T} R Y+Q S Q-Q+(1+\varepsilon)(G Q+H Y)^{T} Q^{-1}(G Q+H Y)+\left(1+\varepsilon^{-1}\right) \alpha^{2}$

$\left[\left(\begin{array}{ll}G & H_{q}\end{array}\right)\left(\begin{array}{cc}A_{p} & 0 \\ 0 & A_{p}\end{array}\right)\left(\begin{array}{c}Q T \\ B Y\end{array}\right)\right]^{T}\left[\left(\begin{array}{cc}G & H_{q}\end{array}\right)\left(\begin{array}{cc}A_{p} & 0 \\ 0 & A_{p}\end{array}\right)\left(\begin{array}{c}Q T \\ B Y\end{array}\right)\right] \leq 0$

let $K=Y Q^{-1}, P=Q^{-1}$, then (23) is equivalent to

$$
\begin{gathered}
(1+\varepsilon)(G+H K)^{T} P(G+H K)+\left(1+\varepsilon^{-1}\right)(\Delta G+\Delta H K)^{T} P(\Delta G+\Delta H K) \\
-P+S+K^{T} R K \leq 0
\end{gathered}
$$

according to fact 1 , it can be concluded that (24) holds if the following inequality holds.

$(G+H K)^{T} P(G+H K)+2(G+H K)^{T} P(\Delta G+\Delta H K)$

$+(\Delta G+\Delta H K)^{T} P(\Delta G+\Delta H K)-P+S+K^{T} R K \leq 0$ let $V_{k}=x(k)^{T} P x(k)$, then

$$
\begin{aligned}
\Delta V_{k}= & x(k)^{T}\left[(G+H K)^{T} P(G+H K)+2(G+H K)^{T} P(\Delta G+\Delta H K)\right. \\
& \left.+(\Delta G+\Delta H K)^{T} P(\Delta G+\Delta H K)-P\right] x(k) \leq-x(k)^{T}\left[S+K^{T} R K\right] x(k)
\end{aligned}
$$

so, system (3) is quadratically stable under the control of the guaranteed cost controller (22). The sampled-data systems as shown in Fig. (1) is certainly guadratically stable, too.

\subsection{Design of the Optimal Guaranteed Cost Controller}

In this section, we shall exploit the parametrized representation of guaranteed cost controllers for the system as shown in Fig. (1) to present a design procedure for the optimal guaranteed cost controller which minimizes the guaranteed cost of the closed-loop uncertain system.

According to (18) and (19), it can be derived that if the following optimization problem has a solution, then the controller $u(k)=K x(k)$ is the optimal guaranteed cost controller. As a result, we obtain the following theorem.

$$
\begin{aligned}
& \left\{\begin{array}{l}
\min \gamma \\
\text { s.t. } x(0)^{T} P x(0) \leq \gamma \\
\text { Inequality }
\end{array}\right.
\end{aligned}
$$

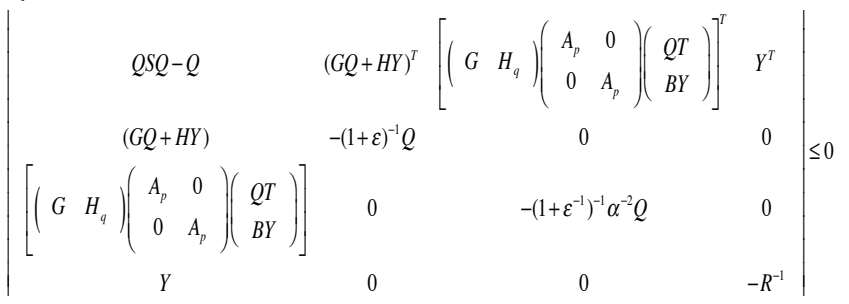

Theorem 4 If the following optimization problem

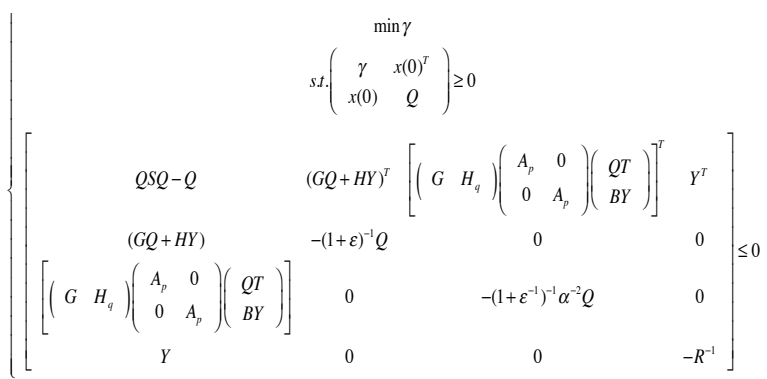




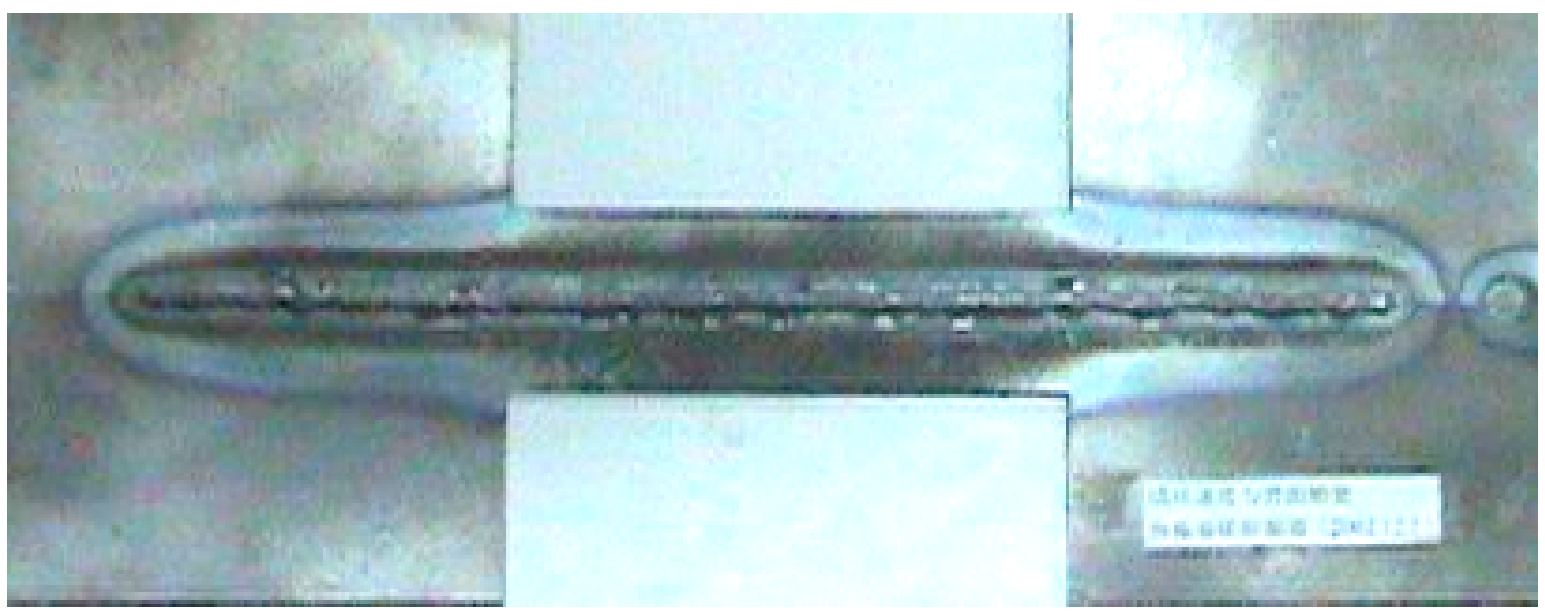

Fig. (2). Weld workpiece of welding speed to backside width of weld pool with robust controller in case of varied heat sink.

has a solution $\gamma \in \mathfrak{R}^{+}, 0<Q^{T}=Q \in \mathfrak{R}^{n \times n}, Y \in \mathfrak{R}^{m \times n}$

Then, control law of the form (22) is the optimal state feedback guaranteed cost controller which ensures the minimization of the guaranteed cost for the uncertain system (1).

Proof The proof of this theorem can be given by combining theorem 2 with 3.

\section{APPLICATION IN GAS TUNGSTEN ARC ELDING SYSTEM}

The gas tungsten arc welding dynamic process is a typical control system with uncertainties as well as time-delay . In this system the input is welding speeding and the output is Width of weld pool backside.

\subsection{Mathematics Model and Controller}

By using the sensing system of weld pool's image, the weld shape parameters can be got so that some varying data of the backside width of weld pool to the pulse duty ratio can be obtained. The correlative experimental condition is as follows:

Welding current: Base value $35 \mathrm{~A}$

Peak value $135 \mathrm{~A}$

Welding speed: 0-30pulses $16 \mathrm{~cm} / \mathrm{min}$

$31 \sim 50$ pulses $13 \mathrm{~cm} / \mathrm{min}$

Pulse duty ratio: $45 \%$

The other experimental conditions are shown in Table $\mathbf{1 .}$

Table 1. Experimental Conditions of Pulsed GTAW

\begin{tabular}{|c|c|c|c|}
\hline Parameter Name & $\begin{array}{c}\text { Parameter } \\
\text { Number }\end{array}$ & Parameter Name & $\begin{array}{c}\text { Parameter } \\
\text { Number }\end{array}$ \\
\hline \hline Welding material & Q235B & $\begin{array}{c}\text { Electro-arc length, } \\
l / \mathrm{mm}\end{array}$ & 3.0 \\
\hline $\begin{array}{c}\text { Pulse frequency } f / \mathrm{Hz} \\
\text { Base value of current } \\
I_{b} / \mathrm{A}\end{array}$ & 1 & $\begin{array}{c}\text { Diameter } \\
\text { of tungsten } d / \mathrm{mm}\end{array}$ & 3.0 \\
\hline
\end{tabular}

\begin{tabular}{|c|c|c|c|}
\hline $\begin{array}{c}\text { Flow of argon } q_{v} \\
/\left(\mathrm{L} \cdot \mathrm{min}^{-1}\right)\end{array}$ & 8.0 & $\begin{array}{c}\text { Size of welding } \\
\text { workpiece } V / \mathrm{mm}^{3}\end{array}$ & $250 \times 100 \times 2$ \\
\hline
\end{tabular}

With the square method the transfer function of the backside width of weld pool to the pulse duty ratio is identified as

$G(s)=\frac{3.4718}{5.0021 s^{2}+4.0402 s+1.0} e^{-2 t}$

while the welding process is in steady state, its mathematics model in the state space is

$$
\begin{aligned}
& x(t)=\left[\begin{array}{cc}
0 & 1 \\
-0.194 & -0.8971
\end{array}\right] x(t)+\left[\begin{array}{l}
0 \\
1
\end{array}\right] u(t) \\
& y(t)=\left[\begin{array}{ll}
-0.5486 & 0
\end{array}\right] x(t)
\end{aligned}
$$

By discretizing Eq. (28), the discrete-time nominal system model can be obtained as follows

$$
x(k+1)=\left[\begin{array}{cc}
0.71228 & 0.4116 \\
0 & 0.6329
\end{array}\right] x(k)+\left[\begin{array}{l}
0.0116 \\
0.0699
\end{array}\right] u(k)
$$

Because the state variables in welding process are not all measured physically, the necessary observer with 1dimension is designed as

$z(k+1)=-0.1 z(k)-2.176 y(k)+0.3743 u(k)$

While the robust controller is

$u(k)=-\left[\begin{array}{ll}0.8226 & 0.5399\end{array}\right]\left[\begin{array}{l}x_{1}(k) \\ x_{2}(k)\end{array}\right]$

\subsection{Simulation and Experiment Results}

Fig. (1) shows the simulation curves of the states of the butt GTAW system under the controller (31) with disturbance (random signal) and without disturbance respectively, which describes the satisfied function of the robust controller.

In the welding experiment, the conditions are the same as those in 4.1. Then Fig. (2) shows the welding effect of a weld workpiece when the backside width of weld pool is required to be $5 \mathrm{~mm}$. The practical welding error is less than $5 \%$. 


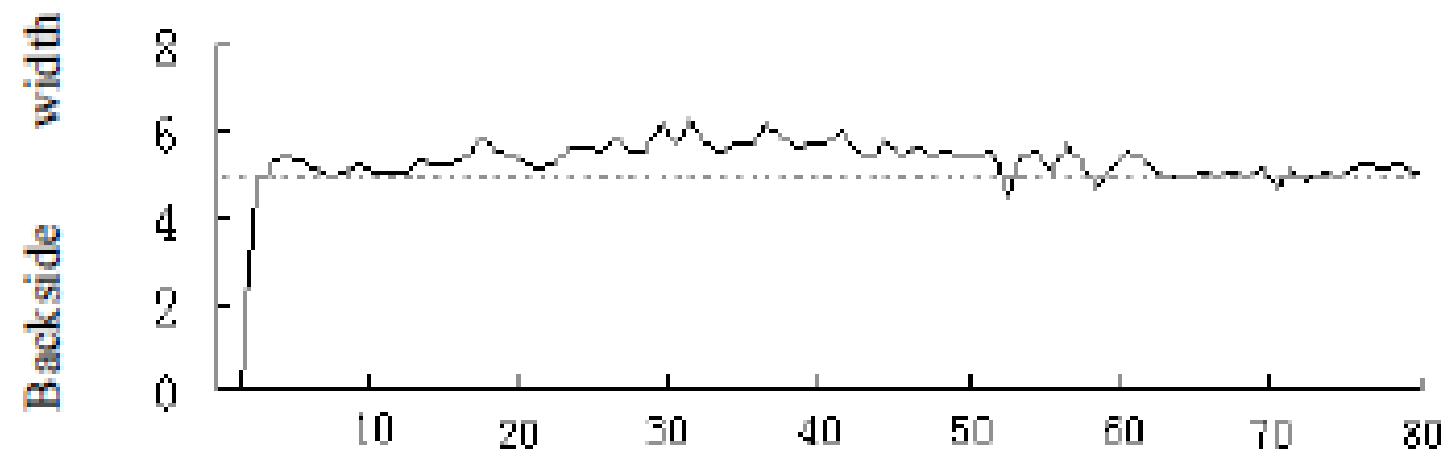

\section{Number of pulse $n$}

Fig. (3). Dynamic response curves of welding speed to backside width of weld pool with PID controller under the condition of varied heat sink.

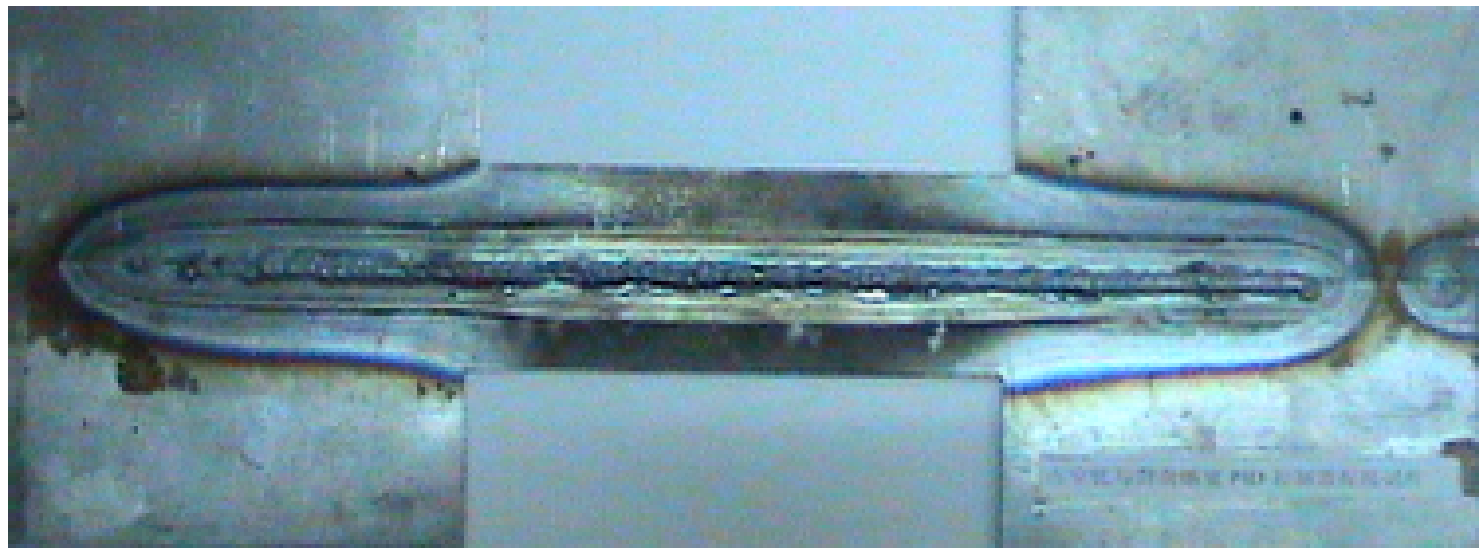

Fig. (4). Weld workpiece of welding speed to backside width of weld Pool with PID controller under the condition of varied heat sink.

Under the same experimental conditions, with the utility of self-finding optimality the parameters of PID controller are adjusted. When the backside width of weld pool is $5 \mathrm{~mm}$, the parameters can be got as follows

$$
K_{\mathrm{P}}=18.5 \quad T_{\mathrm{I}}=1.95 \quad T_{\mathrm{D}}=0.5
$$

Then the simulation response curves of the butt GTAW system under the PID controller with disturbance unknown in the practical welding situation and the real welding effect of a weld workpiece are shown in Fig. (3) and Fig. (4) respectively.

From Fig. (3) and Fig. (4) it is not difficult to know that when the heat-sink condition goes so bad that the adjustment function of the PID controller to such a dynamic process with disturbance is not preferable, and the backside width of weld pool behaviors as curves similar to saw-tooth waves during about 24 th $\sim 52$ th pulse. The practical welding error is nearly $23 \%$.

\section{CONCLUSION}

By using the second method of Lyapunov and an LMI approach, this paper studies robust control and robust optimal control for sampled-data systems with structured uncertainty. The guaranteed cost control law and the optimal guaranteed cost control law are derived. These control laws are designed by solving a class of linear matrix inequalities and a class of dynamic optimization problem with LMIs constraints respectively. In the practical welding process the robust controller has better effect than the classical PID controller under the same experimental conditions.

\section{CONFLICT OF INTEREST}

The authors confirm that this article content has no conflicts of interest.

\section{ACKNOWLEDGEMENTS}

This work was supported by the National Nature Science Research fund (No.50975068) and the Scientific Research Creative fund of the city of Harbin (No.2009RFXXG032)

\section{REFERENCES}

[1] Y.C. Li, and X.M. Xu, "The quadratic stability of a discrete-time system with structured uncertainties". Int. J. Contr., vol. 72, no. 16, pp. $1427-1435,1999$

[2] M. S. Mahmoud, "Linear parameter-varying time-delay systems: stability and $\mathrm{l}_{2}$-gain controllers", Int. J. Contr., vol. 73, no. 6, pp. 481-494, 2000

[3] L. Yu, "Optimal guaranteed cost control of linear uncertain system: an LMI approach", Contr. Theory. Appl., vol. 17, no. 3, pp. 423428,2000 .

[4] L.S. Hu, H.H. Shao, and Y.X. Song, "Sampled-data control for time-delay uncertain linear systems", Control Theory Appl., vol. 17 , no. 3 , pp. $453-456,2000$ 
[5] C.W. Cheng, and B.Y. Tang, "Designing robust stabilization controller for delayed systems with rank type uncertainties LMI approach", Acta. Auto. Sin., vol. 26, no. 2, pp. 278-281, 2000.

[6] E. Jelel, "Robust stability bounds for sampled-data systems: the unstructured perturbation case", Am. Contr. Conf., pp. 3353-3357, 1995.

[7] D. Geir and G. Keith, "Analysis of structured LTI uncertainty in sampled-data systems", Automatica, vol. 31, no. 1, pp. 99-113, 1995.

[8] W. Qiang, J.F Wu, and L. Zhi-Dong, "Robust stability for sampleddata systems in structured perturbation case", J. Elect. Mach. Cont., vol. 3, no. 4, pp. 223-227(in Chinese), 1999.

[9] J.F Wu, S.B Chen, and M.J Zhang, "Robust control of gas tungsten arc welding system", Mech. Eng., vol.20, no.5, pp. 32-36, 2006.

[10] W. Junfeng, and L.S. Wu. " $H \infty$ Robust Control for a Class of Sample-data Systems with Structured Uncertainties". J. Control Theory Appl., vol. 25, no. 3, pp 21-23, 2006.

[11] W. Junfeng, D. Lizhi, and J. Mingbo. "Robust Control of sampleddata systems with slow tine-varying disturbance based on proportional-integral state observer". Electr. Mach. Cont., vol.12, no. 2, pp 229-233, 2008.
[12] W. Junfeng, C. Shanben, and H. Libo. "Application research for the robust control of the welding process systems with pole constraints". J. Electr. Mach. Cont., vol.10, no. 6, pp. 618-631, 2006.

[13] S. Ping, and W. Junfeng. "D Robust Control of A Class Uncertain Sample-data System”. J. Control. Theory. Appl., vol. 28 no. 9, pp. 7- 10; 25, 2009.

[14] W. Junfeng, L. Shan, and W. Hongfei. "Robust control of sampleddata systems with norm-bounded uncertainty". J. Harbin Inst. Technol., vol.41, no.1, pp.189-192.

[15] F. Liying, W. Junfeng, L. Hongliang, and W. Shigang. "Variable sampling control for uncertain system". J. Electr. Mach. Cont., vol. 15 no. 11, pp. 90-94, 2011.

[16] L. Jixiang, W. Junfeng, and F. Liying. "D-stable robust non-fragile reliable control for uncertain discrete singular systems". J. Central South Uni. Sci. Technol., 42 (6), pp. 1670-1675, 2011.

[17] W. Shigang, and W. Junfeng. "Observer based non-fragile $H \infty$ control for a class of uncertain time-delay sampled-data systems". J. Syst. Eng. Electr., vol. 33, no. 6, pp.1352-1357, 2011.

[18] W. Junfeng, W. Qiang, and C. Shanben. "Robust Stable for Sample-Data Systems". J. Control Theory Appl., 18, pp. 99-102, 2001.

Received: February 23, 2012

(C) Wu et al.; Licensee Bentham Open.

This is an open access article licensed under the terms of the Creative Commons Attribution Non-Commercial License (http://creativecommons.org/licenses/by-nc/3.0/) which permits unrestricted, non-commercial use, distribution and reproduction in any medium, provided the work is properly cited. 